\title{
Acessibilidade em edifícios de múltiplos usos mediada pela ergonomia
}

\author{
CALVET, Juliane ${ }^{1}$ \\ ABRAHÃO, Julia ${ }^{2}$ \\ 1Universidade de Brasília, Brasília, Brasil. arq.julianecalvet@gmail.com \\ 2Universidade de Brasília, Brasília, Brasil. julia.abrahao@gmail.com
}

\begin{abstract}
Resumo
Edifícios de múltiplos usos é um dos principais produtos do mercado imobiliário e, à medida que se multiplicam, nem sempre consideram as necessidades reais das pessoas com mobilidade reduzida PMR. O presente estudo analisa a acessibilidade de dois edifícios visando identificar os problemas decorrentes das inadequações dos edifícios de múltiplos usos relacionados à acessibilidade à luz da NBR 9050. Para tanto, agrega conceitos de ergonomia como suporte visando avaliar se os critérios adotados desde o projeto arquitetônico asseguravam as necessidades e limitações do usuário, bem como seu conforto durante o deslocamento.

O método foi composto por um conjunto de etapas com objetivos distintos: - Analisar as plantas dos edifícios e as características dos usuários PMR; - Simular graficamente na planta as possibilidades de circulação/obstrução; - Validar por meio de visita guiada, identificando as dificuldades e estratégias do usuário nos diferentes percursos. A metodologia adotada tem como pressupostos à análise da situação real e à participação do usuário no processo.

Os resultados apontam barreiras em acessos importantes e mesmo quando os padrões normativos são contemplados, nem sempre o conforto é assegurado. Malgrado, a fragilidade dos dados, o estudo propõe uma reflexão sobre o papel das normativas, apontando sobretudo seus limites.
\end{abstract}

Palavras-Chave: Acessibilidade, Ergonomia, Edifícios Múltiplos Usos, Normas Brasileiras, Inclusão social.

\begin{abstract}
Mixed use buildings are one of the main products of the real estate market and, as they multiply, they do not always consider the real needs of persons with reduced mobility - PRM. The present study analyzes the accessibility of two buildings in order to identify the problems arising from the inadequacies of the multifunctional buildings regarding the accessibility normative of the NBR 9050. therefore, it adds ergonomic concepts as support to evaluate if the criteria adopted since the architectural design ensured the needs and limitations of the user, as well as their comfort while moving.

The method consisted of a series of steps with distinct objectives: - Analyzing the plans of the buildings and the characteristics of the PRM users; - Simulating graphically in the blueprints the circulation/obstruction possibilities; - Validating through a guided tour, identifying the difficulties and strategies of the user in the different routes. The methodology adopted has as a presupposition the analysis of the current situation and the participation of the user in the process. The results point to barriers in important accesses and even when normative standards are contemplated, comfort is not always ensured. Despite, the fragility of the data, the study proposes a reflection on the role of the normative, particularly pointing their limits.
\end{abstract}

Key-Words: Accessibility, Ergonomics, Mixed Use Buildings, Brazilian regulations, Social inclusion. 


\section{Introdução}

A acessibilidade vem ocupando um espaço importante na sociedade, na medida em que o paradigma a respeito das pessoas com mobilidade reduzida - PMR encontra-se em um processo de transformação social. Historicamente, as pessoas com sob essas condições, em sua grande maioria, viviam em espaços restritos sem autonomia. Os dados coletados em 2013 pelo Instituto Brasileiro de Geografia e Estatística (IBGE) em parceria com o Ministério da Saúde, aponta que 6,2\% da população no Brasil possuí algum tipo de deficiência ou incapacidade. O percentual apresentado justifica a importância da discussão do tema na sociedade. Portanto, assegurar a possibilidade de ir e vir em qualquer situação, é responder a uma demanda social importante no Brasil.

Desde meados dos anos 1970, as exigências quanto à qualidade do ambiente construído aumentaram levando as empreiteiras a se preocuparem com a questão da acessibilidade. Acompanhando este desenvolvimento e as mudanças culturais na sociedade demandavam um espaço social extramuros para inclusão de pessoas com algum tipo de deficiência. Assim, esta questão foi operacionalizada, tanto pela definição de normas (ABNT), quanto pelo Ministério das Cidades que disponibiliza uma série de programas visando integrar os requisitos de acessibilidade, especialmente no âmbito da arquitetura e do urbanismo.

Em março de 2018 foi aprovado o decreto n`9.296 cuja a concepção e a implementação dos projetos arquitetônicos de hotéis, pousadas e estruturas similares deverão atender aos princípios do desenho universal e ter como referências básicas as normas técnicas de acessibilidade da Associação Brasileira de Normas Técnicas - ABNT. Sendo assim, considerando que a normativa é uma orientação para o dimensionamento dos espaços, contribuindo para acessibilidade plena apoiada no princípio do direito de ir e vir, porque o decreto se limita apenas à rede hoteleira? Os demais espaços não são frequentados por PMR?

Malgrado a legislação vigente, mesmos nos edifícios mais recentes, a questão da acessibilidade é respondida de forma parcial, criando obstáculos ao uso pleno dos espaços por PMR. Quando o tema é acessibilidade a maioria das incorporadoras/construtoras e até mesmo os próprios usuários PMR, ao serem contatadas, se esquivam como ocorreu neste estudo.

Edifícios de múltiplos usos, objeto deste estudo, são considerados como um dos principais produtos do mercado imobiliário. No entanto, à medida que estes empreendimentos se multiplicam, nem sempre integram as necessidades reais do usuário, e sobretudo as normas técnicas nas diferentes fases de vida do empreendimento. Um dos pré-requisitos fundamentais a ser avaliados no desempenho desses edifícios referem-se à condição de acessibilidade plena. Estes empreendimentos poderiam facilitar o acesso pleno as PMR acompanhando a tendência e os novos modelos de vida familiar possibilitandoIhes a autonomia, ao disponibilizar aos seus moradores áreas de lazer que facilitasse sua socialização.

O presente estudo busca analisar os problemas decorrentes das inadequações dos edifícios de múltiplos usos, ao modo de funcionamento relacionados a acessibilidade de pessoas com mobilidade reduzida. $O$ pressuposto deste estudo parte do princípio que as PMR, podem ter sua deficiência minimizada à medida que the sejam oferecidos recursos para que sua relação com o espaço seja possível, sem os constrangimentos aos quais são submetidos atualmente. Suas limitações físicas determinam os parâmetros no campo da supressão das barreiras arquitetônicas, estabelecendo assim grupos com condições similares tais como: usuários de cadeiras de rodas, dificuldade ambulatória parcial, dificuldades sensoriais, idosos e carrinho de bebês. O cadeirante foi escolhido para o objeto do recorte deste estudo, partindo do pressuposto que o espaço ocupado pela cadeira de rodas permite também o fluxo dos demais (idoso, obeso, portadores de muletas...), pois as dimensões exigidas para os cadeirantes comportam os outros PMR.

Nesta perspectiva, integra-se de forma articulada, ao escopo deste estudo, as Normas Técnicas 
9050/2015, os projetos arquitetônicos e os pressupostos da Ergonomia, possibilitando que requisitos técnicos sejam difundidos visando maior democratização do uso de espaços bem como uma visão mais abrangente da atividade profissional do arquiteto.

\section{Ergonomia e espaço}

A ergonomia se desenvolveu ao longo dos anos e se consolidou pelas demandas sociais. Apoiada em métodos e técnicas de análise própria, a ação ergonômica busca respostas aos problemas resultantes das inadequações dos artefatos, da organização das ações e dos ambientes ao funcionamento humano. Segundo Ledoux (2000), "o ergonomista contribui na reflexão sobre a importância da elaboração do projeto de funcionamento, antes da redação de um programa arquitetônico". Os resultados dessa ação visam a transformação das situações e das condições de uso apoiada em critérios de qualidade, conforto e eficiência. Portanto, "a noção de intervenção ergonômica num projeto arquitetônico abrange situações mais amplas que vão das recomendações para a disposição final dos locais à assistência ao empreendedor no acompanhamento do conjunto do processo de concepção" (MARTIN, 2007).

A ação ergonômica, tem como um de seus objetivos revelar a complexidade das situações. Para tanto, dois conceitos são norteadores em uma Ação ergonômica: a diferença entre a situação prescrita, neste estudo o projeto considerado a tarefa -, e a atividade - ou seja, o uso do espaço. Esta distinção favorece uma análise do uso real do espaço por pessoas com características diferenciadas. Neste sentido, ocupam um espaço importante na análise de projeto, mesmo que haja uma diferença significativa entre o previsto (prescrito) e o real pois, os pressupostos adotados no projeto definem o modo de pensar em uma determinada situação. Segundo Abrahão (2009), "a distinção entre tarefa e atividade remonta aos primórdios da ergonomia". Nesse sentido, são dois conceitos fundamentais e, portanto, tem sua importância nas situações de projeto.

A ergonomia e a arquitetura unem-se pelo planejamento e pela investigação das atividades, considerando tanto uma visão sistêmica do espaço como o processo de concepção arquitetônica desse sistema. "Por meio da ergonomia, é possível entender as atividades humanas e os seus requisitos de desenho. Por meio da arquitetura, é possível oferecer os elementos para que as atividades se realizem" (PATTERSON, 2010). Assim sendo, pode-se afirmar que a ergonomia está estreitamente relacionada ao espaço, buscando soluções de projeto e adaptações de forma a assegurar o conforto, integrando as características da população tanto as exigências de uso, quanto o dimensionamento do espaço.

\section{Ergonomia e Acessibilidade}

Acessibilidade e Ergonomia são complementares na medida em que ambas têm como preocupação o conforto e a segurança do usuário. A partir da ergonomia é possível a definição de parâmetros para o desenvolvimento de projetos acessíveis, na medida em que seus métodos integram a análise do uso e como se dá a interação do usuário com o meio. Dado o reconhecimento da interdisciplinaridade, a sua relação com a arquitetura estende-se tanto para definição dos espaços acessíveis quanto aos materiais e soluções de design de diferentes equipamentos presentes nas cidades e em edifícios habitacionais. Segundo Béguin (2007a) e Martin (2007): "A identificação, a análise e a recomposição das variáveis que modulam as atividades em parâmetros de desenho revelam a importância da ação ergonômica na fase de programação do projeto arquitetônico".

As barreiras arquitetônicas dos ambientes construídos são um dos maiores entraves para se atender aos parâmetros de acessibilidade. E, para que o uso dos ambientes ocorra de maneira autônoma e segura, associa-se neste estudo os pressupostos da ergonomia visando facilitar o uso e diminuir o esforço no desempenho das atividades. Do mesmo modo, a ergonomia torna-se importante suporte para a segurança e a eficiência do ambiente construído, melhorando seu nível de desempenho e ampliando a visão da situação real, a fim de otimizar o bem-estar humano. 
Os conhecimentos em ergonomia resultam de estudos de campo o que a caracteriza como uma área aplicada, pois tradicionalmente a ação ergonômica visa responder a uma demanda, no caso específico às PMR. Segundo Abrahão (2009): "Os ergonomistas contribuem para o planejamento, projeto e a avaliação de tarefas, postos de trabalho, produtos, ambientes e sistemas de modo a torná-los compatíveis com as necessidades, habilidades e limitações de pessoas". Desta forma, pode-se afirmar que a ergonomia está estreitamente relacionada ao espaço habitado, na medida em que busca soluções de projeto, tendo como critério o conforto e minimizando os entraves que ocorrem na livre circulação dos PMR. A ação ergonômica vai além do diagnóstico, intervenção e concepção, implica também, em agregar à prática ergonômica a participação dos usuários. Darses e Reuzeau (2007) “...Enfatizam as possibilidades de melhoria das condições de trabalho por meio da concepção participativa" com foco nas reais necessidades dos usuários e de suas expectativas em relação ao projeto, prevalecendo a primazia do ser humano nas situações de resolução do problema.

\section{O Método}

O modelo metodológico proposto por Guérin et al (2001), guardando as especificidades requeridas no objeto de estudo, permite "tratar um problema e resolver uma demanda", (Daniellou \& Béguin, 2007). Tal pressuposto se sustenta se o consideramos como sendo um método interativo e apropriado para revelar a complexidade das situações.

Com base nos conceitos oriundos na Ergonomia, a Análise Ergonômica do Trabalho - AET, foi construída inicialmente voltada para analisar os ambientes de trabalho. No entanto, com o decorrer do tempo, diferentes estudos, em ergonomia tem demonstrado sua utilidade no processo de concepção e/ou avaliação de projetos.

Neste estudo, o método proposto (Figura 01) é constituído por um conjunto de etapas e ações, possibilitando a validação dos resultados obtidos em cada uma delas. Na definição das etapas, considerar a perspectiva, em que a atividade é o eixo norteador do processo de investigação, favorece que as condições físicas do espaço sejam resultantes das atividades existentes ou futuras.

O método proposto analisa o projeto e a situação real de uso das PMR, buscando verificar se os parâmetros estabelecidos pelas normas de acessibilidade contemplam também os critérios de conforto e de segurança no uso dos espaços.

A seleção dos dois edifícios para o estudo de caso, foi definida pela possibilidade de acesso ao campo. Cinco construtoras/incorporadoras foram contatadas e somente duas disponibilizaram informações e materiais (projetos de arquitetura) para pesquisa com enfoque na acessibilidade dos edifícios. As demais empresas alegaram que o tema do estudo poderia prejudica-los, relatando que existiam problemas de acessibilidade nos projetos desenvolvidos pelas mesmas. A amostra reduziu-se a um sujeito pela dificuldade em encontrar outros que aceitassem participar do experimento. Pode-se supor que esta dificuldade advém do constrangimento de se expor em ambientes que usualmente ainda não fazem parte do seu cotidiano ou, mesmo medo de passar por situações de desconforto. O sujeito da pesquisa é um cadeirante com boas condições físicas e a testagem foi realizada com uma cadeira manual $(75 \mathrm{~cm})$ para o primeiro edifício e com outra automática $(60 \mathrm{~cm})$ para o segundo edifício, com o intuito de avaliar a variabilidade dos equipamentos de manobra.

No primeiro edifício analisado a média percentual de usuários PMR (locatários, proprietários e visitantes) é de $20 \%$ e no segundo $15 \%$. Os percentuais apresentados justificam-se devido à variedade de serviços que os edifícios oferecem na parte comercial, apontando para a diversidade dos usuários. Os primeiros dados sobre o usuário PMR para análise da demanda, ofereceu oportunidade de agregar a realidade aos elementos contextuais dos edifícios. Uma vez identificada as características do usuário, partiu-se para a compreensão da locomoção nas áreas de circulação comum. 
A metodologia adotada neste estudo é composta por três etapas distintas que se retroalimentam, são elas: analisar, simular e validar, em um procedimento retroalimentado por cada uma das etapas da coleta de dados. O pressuposto deste método implica considerar a situação real e o envolvimento do usuário no processo.

Figura 1: Processo de análise da acessibilidade.

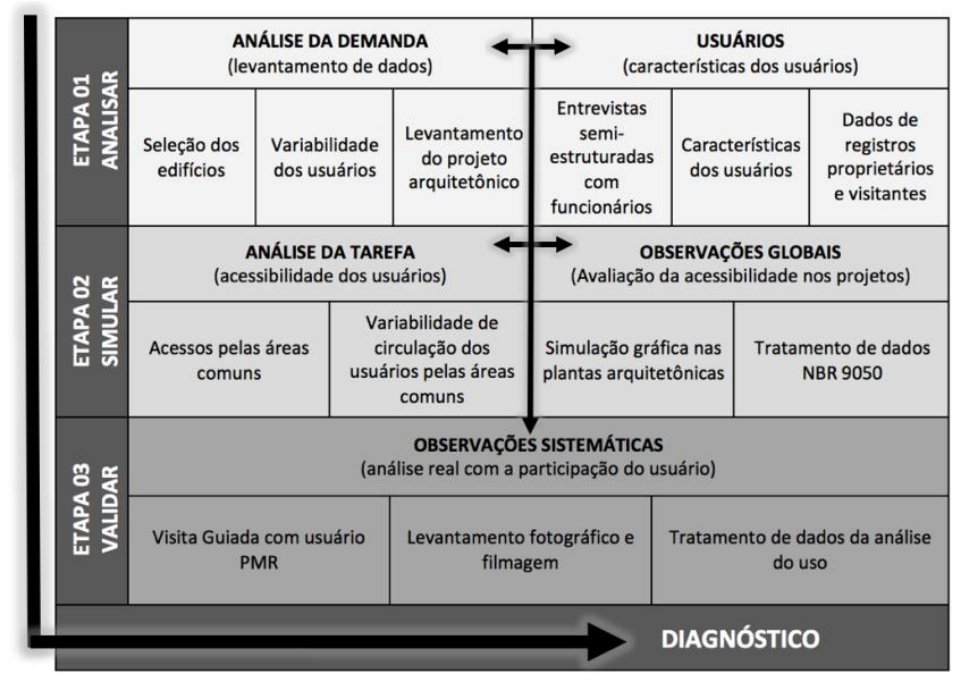

Fonte: J. Calvet (2017)

\subsection{Procedimentos e instrumentos}

\subsubsection{Etapa 1: Analisar}

$\mathrm{Na}$ construção da análise da demanda dos estudos de caso considerou-se a variabilidade (escolha do cadeirante) do sujeito envolvido e o levantamento dos projetos arquitetônicos dos edifícios.

Uma vez definido os edifícios, buscou-se identificar as características dos usuários, por meio de entrevistas semiestruturadas com os funcionários (porteiro e administrador). Os dados coletados foram validados pela via do registro de acesso dos usuários no sistema das portarias e administração. Conhecer os usuários foi fundamental, pois auxiliou a entender as adaptações necessárias à diversidade de dimensionamento e das capacidades motoras das pessoas. Além disso, este procedimento permitiu obter dados relativos ao fluxo e às características dos usuários.

\subsubsection{Etapa 2: Simular}

A análise da tarefa implica no entendimento dos parâmetros de acessibilidade das áreas comuns dos projetos arquitetônicos dos edifícios e na compreensão do que ele determina ao usuário como forma de locomoção. Conforme os conceitos oriundos da ergonomia, a tarefa determina os "modos operandi", de maneira a delimitar as possibilidades de circulação, e ao mesmo tempo é a partir da tarefa e dos seus componentes que é possível a circulação dos usuários. Fazem parte do universo da tarefa, desde o projeto arquitetônico, a disposição das áreas e as ferramentas disponíveis para melhorar o acesso dos usuários entre outros (ABRAHÃO, 2009).

As observações globais permitiram reorganizar os dados técnicos da situação analisada. Os dados de natureza técnica foram coletados por meio de simulação gráfica nas plantas arquitetônicas dos edifícios dos dois estudos de caso, visando analisar o grau de circulação/ obstrução das edificações e as possibilidades de giro/ circulação de um usuário de cadeira de rodas. Neste sentido acompanha-se Martin (2007) ao afirmar que: "A preparação de simulações exige tanto uma construção técnica (em especial a identificação das situações de ação características) quanto uma construção social visando posicionar a modalidade de ação em relação ao conjunto dos atores envolvidos". 
Os resultados deste procedimento permitiram determinar a viabilidade de uso das edificações por idosos, obesos, carrinhos de bebês e todos os outros usuários com mobilidade reduzida. Por meio deste procedimento, foram identificadas e definidas as diferentes possibilidades de locomoção no edifício, desde a portaria de entrada até o local de uso.

A simulação gráfica também permitiu uma avaliação dos critérios à luz da norma brasileira NBR 9050, tendo como eixo norteador a investigação das ações possíveis para os usuários PMR. Na análise dos projetos arquitetônicos dos edifícios, nas áreas comuns, considerou-se as dimensões referenciais da norma: projeção do piso de 0,80×1,20 (Figura 02) medida ocupada por uma pessoa utilizando cadeira de rodas (PCR) e das áreas de manobra de cadeira de rodas.

Figura 2: Módulo da cadeira de rodas e símbolo utilizado em situação de constrangimento.

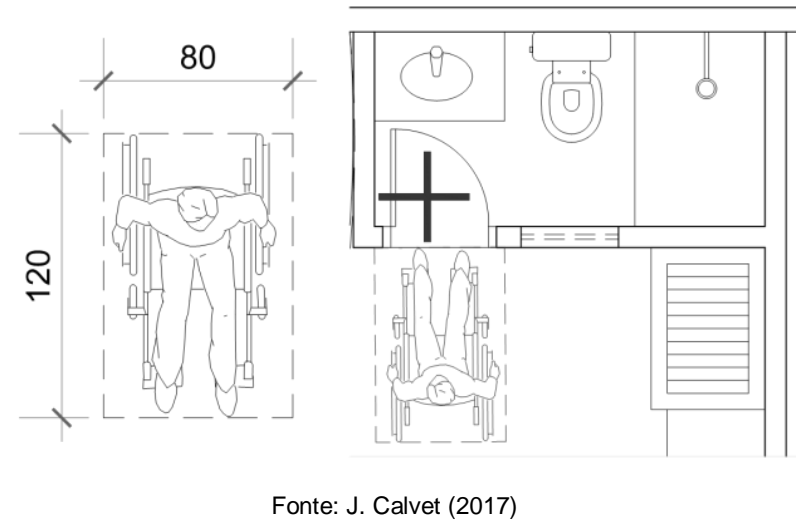

Após o tratamento dos dados desta etapa, com o intuito de validá-los procedeu-se observações de forma sistematizada, visando verificar se os problemas identificados pela simulação gráfica constituíam efetivamente obstáculos para a acessibilidade e se foram detectadas todas as barreiras de acesso nos edifícios.

\subsubsection{Etapa 3: Validar}

A observação sistemática foi o procedimento que permitiu identificar comportamentos e manobras elaboradas pelo sujeito PMR para vencer as barreiras impostas pelo projeto e poder circular. A descrição destes comportamentos buscou assegurar a coerência de variáveis permitindo a coleta de dados úteis a compreensão da atividade. A observação para a análise ergonômica foi participativa, com o objetivo de qualificar as ações e operações do usuário. Para a observação participativa foi adotado o método da visita guiada que consiste em uma visita supervisionada nos dois edifícios dos estudos de caso, percorrendo o mesmo caminho definido anteriormente na simulação gráfica, na companhia do convidado cadeirante e do pesquisador.

No processo de validação a visita guiada na situação real, contribuiu para compreender como ocorriam as ações do PMR, identificando suas dificuldades e as estratégias adotadas por ele durante o caminho. Os percursos foram iniciados na calçada do edifício, e foram finalizados no pavimento tipo de cada categoria (comercial e residencial). No decorrer dos percursos, o participante manifestou sua opinião sobre as facilidades e os problemas encontrados ao longo do caminho e também foram registradas as situações significativas que ocorreram por meio de anotações, fotografias e filmagens. Os dados resultantes foram confrontados e articulados de forma a gerar um diagnóstico dos edifícios quanto às suas condições de acessibilidade.

\section{Resultados e Discussão}


$\mathrm{Na}$ análise dos projetos arquitetônicos (térreo, mezanino e pavimento tipo) dos dois estudos de caso, realizados por meio da simulação gráfica e apoiada nos critérios da norma brasileira NBR 9050, foi possível constatar que os parâmetros de medidas preconizados pela norma de acessibilidade não foram contemplados em alguns ambientes, principalmente nas áreas comuns.

Para melhor entendimento dos critérios exigidos pela norma de acessibilidade NBR 9050/2015, elaborou-se uma tabela de análise (figura 03) com os resultados da simulação gráfica realizada nos projetos dos dois edifícios. Na tabela foram especificados os ambientes/ equipamentos analisados nos projetos arquitetônicos e se foram atendidos os critérios exigidos pela norma.

Figura 3: Desempenho de Acessibilidade da ABNT NBR 9050/2015.

\begin{tabular}{|c|c|c|c|c|c|c|}
\hline \multirow{2}{*}{$\begin{array}{c}\text { AMBIENTESI } \\
\text { EQUIPAMENTOS }\end{array}$} & \multicolumn{3}{|c|}{$\begin{array}{c}\text { ATENDIMENTO AOS } \\
\text { CRITÉRIOS DA ABNT NBR } \\
\text { 9050/2015 } \\
\text { ESTUDO DE CASO } 01 \\
\end{array}$} & \multicolumn{3}{|c|}{$\begin{array}{c}\text { ATENDIMENTO AOS } \\
\text { CRITÉRIOS DA } \\
\text { ABNT NBR 9050/2015 } \\
\text { ESTUDO DE CASO } 02 \\
\end{array}$} \\
\hline & Térreo & Mezanino & Pay. tipo & Térreo & Mezanino & Pay. tipo \\
\hline Estacionamento & $x$ & - & - & $\checkmark$ & - & - \\
\hline Hall & $x$ & $\checkmark$ & $\checkmark$ & $\checkmark$ & $\checkmark$ & $\checkmark$ \\
\hline Piso & $\checkmark$ & $\checkmark$ & $\checkmark$ & $x$ & $\checkmark$ & $\checkmark$ \\
\hline Rampas & $\checkmark$ & - & - & $\checkmark$ & - & - \\
\hline $\begin{array}{c}\text { Corrimão e } \\
\text { guarda corpo }\end{array}$ & $\checkmark$ & - & - & $\checkmark$ & - & - \\
\hline Circulação & $\checkmark$ & $\checkmark$ & $\checkmark$ & $\checkmark$ & $\checkmark$ & $\checkmark$ \\
\hline Portas & $\checkmark$ & $\checkmark$ & $\checkmark$ & $\checkmark$ & $\checkmark$ & $\checkmark$ \\
\hline $\begin{array}{c}\text { Instalações } \\
\text { Sanitárias }\end{array}$ & $\checkmark$ & $x$ & - & $\mathrm{x}$ & $\checkmark$ & - \\
\hline
\end{tabular}

Legenda: X- Não atende aos critérios da norma, $\sqrt{ }$ - Atende aos critérios da norma, --- - não consta o ambiente/ equipamento Fonte: J. Calvet (2017)

Na simulação gráfica realizada no projeto arquitetônico do pavimento térreo no primeiro estudo de caso, identificou-se barreiras que impedem o deslocamento das PMR, como por exemplo ausência de estacionamento reservado para PMR, no hall de entrada o layout apresentado no projeto é inadequado pois a circulação é inacessível para cadeira de rodas, além de possuir uma barreira por meio de catracas, não existindo nenhuma passagem para PMR. Porém identificou-se no projeto critérios em conformidade com a norma, como, a inclinação da rampa, além das circulações, pisos, portas e instalações sanitárias.

$\mathrm{Na}$ avaliação do segundo edifício por meio da simulação gráfica no projeto arquitetônico do pavimento térreo, identificou-se uma evolução projetual em relação ao segundo, o hall de entrada, elevadores e circulações são amplos (medidas superiores às exigidas pela norma) de forma a permitir que o cadeirante faça manobras confortavelmente. Identificou-se a presença de vaga reservada para PMR, as rampas obedecem aos parâmetros de inclinação indicados na norma e uma ampla área externa com circulação confortável. Porém, barreiras também foram identificadas, como desnível no piso ao acessar as áreas destinadas ao descanso no jardim e também as instalações sanitárias que não são adequadas por não apresentarem medidas e equipamentos apropriados e exigidos pela norma para o acesso de PMR.

Em ambos os edifícios, a planta do Mezanino comporta a área de lazer com piscina, churrasqueira e sanitários. O resultado da simulação gráfica nos projetos das áreas de lazer dos edifícios foi a restrição ao acesso à área de piscina pela inexistência de rampa, existindo apenas um acesso que se dá somente por escadas, impedindo o acesso das PMR ao uso do espaço. Quanto aos parâmetros das instalações sanitárias das áreas de lazer somente o projeto do primeiro edifício não atende aos critérios da norma, no projeto do segundo edifício as instalações sanitárias estão adequadas as exigências da normativa. Nos projetos dos pavimentos tipos de ambos os estudos de caso, obedecem aos critérios exigidos pela norma, inclusive nas portas de acesso aos escritório e apartamentos residenciais e elevadores. Com o objetivo de confrontar e por esta via validar as situações identificadas na simulação gráfica nos projetos 
dos edifícios, realizou-se a visita guiada com o cadeirante. Com a visita guiada, foram identificadas novas barreiras em ambos os edifícios como por exemplo, desníveis no piso e desconforto na passagem pelas aberturas da porta, pois não permite um movimento confortável nos braços para o manuseio da cadeira de rodas demostrando que apesar de atender aos parâmetros da norma, esses parâmetros ainda não são "ideais" para o uso confortável dos ambientes. Em ambos edifícios alguns problemas ainda persistem, detectados anteriormente na simulação gráfica aplicada nos projetos arquitetônicos, por exemplo, a ausência e inadequação de instalação sanitária para PMR e o direito ao uso dos espaços, no caso dos dois edifícios avaliados foi a área da piscina/deck.

$\mathrm{Na}$ visita guiada no primeiro edifício, o cadeirante portou uma cadeira de rodas manual ( $65 \mathrm{~cm}$ de largura). No pavimento térreo, a rampa identificada na simulação gráfica do projeto estava conforme as especificações da NBR 9050, porém o cadeirante durante a visita não conseguiu subir de maneira autônoma, solicitando ajuda para chegar até a porta de acesso interna do edifício (figura 04).

Figura 4: Acesso pela rampa com inclinação irregular

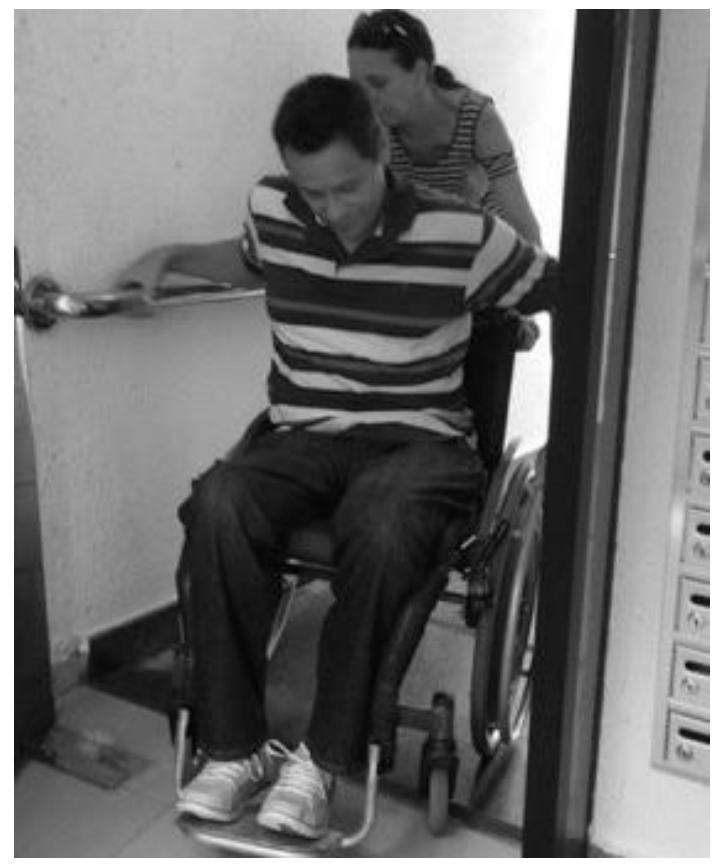

Fonte: J. Calvet (2017)

Também afirmou que não consegue visitar edifícios sozinho, pois sua locomoção nunca é tranquila e segura e que em todos os lugares vivencia situações de constrangimentos. "É muito comum chegar nos lugares e pessoas ajudarem a carregar a cadeira de rodas, pois o único acesso, se dá pelas escadas e quando tem rampas, são muito íngremes, como a deste edifício, sendo impossível a locomoção sem ajuda".

Para a visita guiada do segundo edifício o cadeirante utilizou durante o experimento uma cadeira automática $(60 \mathrm{~cm}$ de largura), com o intuito de verificar se facilitaria a locomoção e amenizaria os problemas que foram encontrados no experimento do primeiro edifício com a cadeira manual. Durante a visita, comprovou-se a facilidade da cadeira automática em algumas situações como nas rampas e no deslocamento de locais com maiores distancias. O participante considerou o edifício com uma boa acessibilidade. "Os edifícios novos estão com espaços de circulação maiores que os de antigamente". Malgrado o fato de não usufruir da área da piscina e nem mesmo a área de descanso do jardim (figura 5), o visitante se conforta pelo simples fato de poder acessar outros espaços e elevadores e manifesta satisfação com o edifício.

Figura 5: Declive para acessar a área de descanso no jardim. 


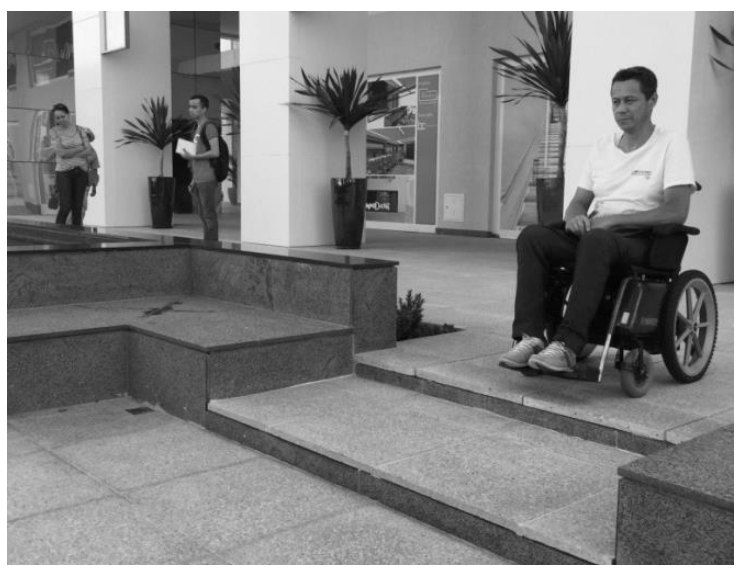

Fonte: J. Calvet (2017)

Ao que tudo indica, não se pensa que os PMR poderiam usufruir desses equipamentos, excluindo-o do direito ao uso dos espaços ou sofrer constrangimentos em ser transportado por outras pessoas para acessar o local que poderia ser importante para seu condicionamento físico, saúde e bem-estar. $O$ visitante demostrou-se conformado e manifestou satisfação em pelo menos ter acesso ao edifício, deixando claro que a exclusão é o habitual nos edifícios da cidade configurando a triste realidade dessas pessoas. "Aconteceu muitas vezes de chegar ao edifício e ter que ir embora, este pelo menos nos dá oportunidade de acesso nas áreas comuns".

Por meio da visita guiada, pode-se identificar a importância da análise de uma situação real na elaboração de um projeto arquitetônico. Os edifícios avaliados carecem de recursos de interação entre usuários e as áreas de uso comum, como pode-se identificar por exemplo no uso da área de lazer (figura $6)$.

Figura 6: Escada para acessar a piscina

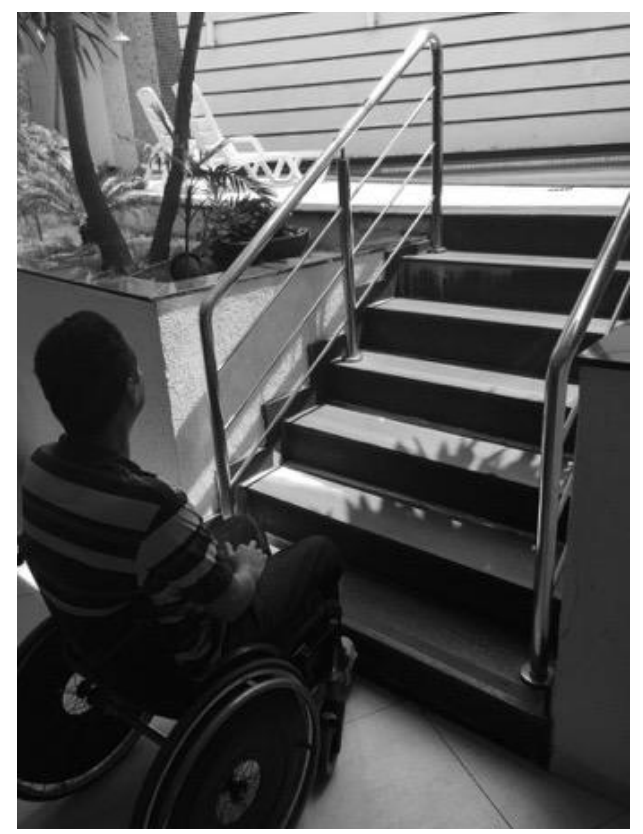

Fonte: J. Calvet (2017)

\section{6. À guisa de conclusão}

O direito ao livre acesso, malgrado o fato de estar contemplado nas legislações federais e consolidado 
por uma série de iniciativas do Ministério das Cidades, ainda é comum se deparar com restrições de autonomia e segurança de PMR no acesso aos edifícios. A norma NBR 9050:2015 apresenta uma série de dimensões referenciais que orientam o dimensionamento dos espaços cujas exigências de acessibilidade se fazem necessárias.

Não desmerecendo a importância da temática, as avaliações realizadas contribuíram para o processo projetual na questão da acessibilidade. Este estudo apontou que ao projetar, obedecendo somente os parâmetros das normas, muitas vezes não se assegura o conforto ao usuário. Os fatos demonstram que na vida real essas medidas nem sempre abarcam a variabilidade dos sujeitos envolvidos, nem tampouco as diferentes possibilidades de uso. A reflexão sobre as questões ligadas à acessibilidade vai muito além dos limites definidos pelas normas. Malgrado, a fragilidade dos dados, este estudo ao propor uma reflexão sobre o papel das normas, aponta sobretudo seus limites.

Nesta perspectiva, constitui um alerta para os atores envolvidos que as normas asseguram as condições mínimas de acesso, apontando para a necessidade de não se apoiar apenas nos parâmetros da NBR 9050:2015, mas, avaliar também se estes parâmetros, definidos na norma, estão atendendo de forma satisfatória e segura os critérios de conforto e segurança. A questão que se coloca face aos resultados, é se o problema está nas normas ou na operacionalização das mesmas nos projetos. Seriam os condicionantes definidos pelas incorporadoras ou pelos projetistas, ainda pouco habituados a integrar de fato os PMR na vida real? Nesta fase do estudo, hipotetiza-se que esta preocupação com a acessibilidade ainda não foi de fato apropriada pelas diferentes categorias profissionais. Pode-se ainda, inferir que esse "faz de conta "de acessibilidade, talvez seja uma questão da cultura local que ainda acredita que os deficientes deviam se manter em espaços restritos. Pensar acessibilidade exige talvez repensar em soluções que realmente permitam integrar o percentual de portadores de deficiência apontados no último censo do IBGE.

Enfim, qual a contribuição do ergonomista na fase de projeto? Contribuir na avaliação de como os espaços previstos determinarão parcialmente a atividade dos futuros usuários identificando as dificuldades prováveis e as modificações que poderiam ser necessárias ainda na fase de projeto. Essas recomendações para o projeto arquitetônico visam facilitar o processo de desenho, assegurando um espaço de qualidade sob a perspectiva de seu usuário, sugerindo a retroalimentação do processo de concepção tais como parâmetros para novos projetos. Assim, talvez seja possível salvaguardar os direitos e ampliar o conceito de acessibilidade em nossa sociedade.

\section{Referências}

Abrahão, J. I., \& Pinho, D. L. M. (1999). Teoria e prática ergonômica: Seus limites e possibilidades. Em M. G. T. Paz, \& A. Tamayo (Orgs.) Escola, Saúde e Trabalho: Estudos Psicológicos. Brasília: Editora UnB.

ABRAHÃO, Júlia; SZNELWAR, Laerte; SILVINO, Alexandre; SARMET, Maurício; PINHO, Diana. Introdução à Ergonomia da prática à teoria. São Paulo: Blucher, 2009.

ASSOCIAÇÃO BRASILEIRA DE NORMAS TÉCNICAS. NBR 9050: Acessibilidade a edificações, mobiliário, espaços e equipamentos urbanos. Rio de Janeiro: 2004. 105p.

NBR 13994: Elevadores de passageiros - elevadores para transporte de pessoa portadora de deficiência. Rio de Janeiro: 2000. 15p.

BÉGUIN, P. (2007a). O ergonomista, ator da concepção. Em P. Falzon (Ed.), Ergonomia (pp. 3463). Rio de Janeiro: Y. H. Lucerna Ltda. (Trabalho original publicado em 1997). 
BRASIL. Constituição (1988). Constituição da República Federativa do Brasil: promulgada em 05 de outubro de 1988. Brasília: Senado, 2006. 54p. Disponível em: www.planalto.gov.br/ccivil_03/constituicao/constituicao. Acesso em 30.06.2014

Legislação. Lei $\mathbf{n}^{\circ} \mathbf{1 0 . 0 9 8}$, de 19 de dezembro de 2000. Estabelece normas gerais e critérios básicos para a promoção da acessibilidade das pessoas portadoras de deficiência ou com mobilidade reduzida, e dá outras providências. Disponível em: http://www.planalto.gov.br/ccivil_03/leis/110098.htm. Acesso em 30.06.2014

Legislação. Decreto $\mathrm{n}^{\circ} \mathbf{9 . 2 9 6}$, de 01 de março de 2018. Regulamenta o art. 45 da Lei $n^{\circ}$ 13.146, de 6 de julho de 2015, que institui a Lei Brasileira de Inclusão da Pessoa com Deficiência Estatuto da Pessoa com Deficiência.

BRASIL. INSTITUTO BRASILEIRO DE GEOGRAFIA E ESTATISTICA. Censo Demográfico 2010. 2012. Disponível em <http://censo2010.ibge.gov.br/> Acesso em 13 dez 2012.

DANIELLOU, F., \& Béguin, P. (2007). Metodologia da ação ergonômica: Abordagens do trabalho real. Em P. Falzon (Ed.), Ergonomia (pp. 281-301). São Paulo: Blücher. (Trabalho original publicado em 2004).

DARSES, F., \& REUZEAU, F. (2007). Participação dos usuários na concepção dos sistemas e dispositivos de trabalho. Em P. Falzon (Ed.), Ergonomia (pp. 343-356). São Paulo: Blücher. (Trabalho original publicado em 2004).

FERREIRA, Luís Oscar. Mobilidade e Acessibilidade - Uma Via para a Reabilitação Arquitetônica e Urbanística. Reabilita Unb, 2014.

GUÉRIN, F., Laville, A., Daniellou, F., Duraffourg, J., \&Kerguelen, A. (2001). Compreender o trabalho para transformá-lo: A prática da ergonomia [Comprendreletravailpourletransformer, la pratique de I"ergonomie]. (G. M. J. Ingratta, \& M. Maffei, Trads.). São Paulo: Blücher. (Trabalho original publicado em 1977).

HUBAULT, F. Ergonomia e condução de projeto arquitetônico. Em Abrahão. J et all, Cadernos de TTO, n³: trabalho, tecnologia e organização (pp.51-103). São Paulo: Blucher, 2012.

LAUTIER, F. (2007). O ergonomista nos projetos arquitetônicos. Em P. Falzon (Ed.), Ergonomia (pp. 357-369). São Paulo: Blücher. (Trabalho original publicado em 1999).

LEDOUX, E. Projetsarchitecturauxdanslesecteursanitaire et social. Du bâtimentauprojet: lacontributiondesergonomes à l'instructiondeschoix. Bordeaux: Université Victor-Segalen, 2000. 